\title{
Ecological Conditions and Benthic Macroinvertebrates of Lake Tinishu Ababya, Ethiopia
}

\author{
Yirga Enawgaw ${ }^{1 *}$ and Brook Lemma ${ }^{2}$ \\ ${ }^{1}$ Department of Biology, Wolkite University, Ethiopia \\ ${ }^{2}$ Department of zoological sciences, Addis Ababa University, Ethiopia
}

Submission: February 18, 2019; Published: July 03, 2019

Corresponding author: Yirga Enawgaw, Department of Biology, College of Natural and Computational Sciences, Wolkite University, Po. Box 07. Wolkite, Ethiopia

Abstract

The ecological condition of Lake Tinishu Abaya was assessed using benthic macroinvertebrates as well. The results from this aspect of the study showed that a total of 5735 benthic macroinvertebrate specimens comprising of 23 taxa were collected from all the study sites. There was spatial effect on the number and distribution of benthic individuals $(\mathrm{p}<0.05)$. It was high at Dacha riverside $(\mathrm{n}=2089)$ followed by Bobodo riverside ( $n=1145)$, Reference site ( $n=963)$, Badober riverside $(n=859)$, and Maingate side $(n=679)$. The abundance of benthic communities significantly varied between the study seasons $(\mathrm{p}<0.05)$. Higher individuals were observed during the wet season $(\mathrm{n}=3583)$ than in the dry season $(n=2152)$. The Hemiptera family were the predominant macroinvertebrates that contributed the largest number $(n=2546)$ of the total samples followed by Diptera $(n=878)$, Coleoptera $(n=835,14.56 \%)$ and Gastropoda $(n=631)$. The Ephemeroptera $(n=172)$, Hirudinae $(n=335)$ and Oligochates $(\mathrm{n}=116)$ were represented by low number of animals. The majority (about $70 \%)$ of the benthic communities of Lake Tinishu Abaya are composed of pollution tolerant species as compared to the presence of pollution sensitive ones $(<30 \%)$ in most of the sampling sites. This indicated that the existence of organic pollution and thus Lake Tinishu Abaya is undergoing environmental stresses. This obviously calls for participatory and interdisciplinary actions of watershed management and wise use of aquatic resources with compliance to commonly set agenda of sustainable use of natural resources.

Keywords: Lake Tinishu Abaya; Macroinvertebrates; Benthic invertebrate; Aquatic; Littoral zone; Intermediary position; Vertebrate predators; Eutrophication pressure;

\section{Introduction}

Benthic macroinvertebrates are one of the key components of lake ecosystems [1]. They form an important link between primary producers, detrital deposits, and higher trophic levels in aquatic food webs [2]. Hence, any environmental changes in lakes, for example in nutrient concentrations, would be reflected by changes in the structure of the benthic invertebrate community. This means that benthic invertebrates may potentially indicate eutrophication, as planktonic communities, but in addition several other modes of lake degradation. In consequence, the more holistic assessment based on benthic invertebrates is expected to result in different classifications than that based on planktonic communities, especially for lakes subjected to multiple impacts [3]. The structure of the benthic communities in an aquatic ecosystem reflects its ecological conditions, including habitat heterogeneity and water quality [4,5]. The use of benthic invertebrate communities as indicators of environmental degradation or restoration has become widespread and reliable for bioassessment since the benthos broadly reflect environmental conditions [6]. Among the biological communities that are considered bioindicators of water quality, the most commonly used are the benthic macroinvertebrates $[7,8]$, because they have several characteristics that make them easy to study and show clear responses when faced with adverse environmental conditions.

Different groups of macroinvertebrates are excellent indicators of human impacts, especially contamination [9]. Most of them have quite narrow ecological requirements and are very useful as bioindicators in determining the characteristics of aquatic environments [10], to identify the segments of a polluted river where self-purification of organic inputs is under process [11]. The littoral zone of lakes plays a crucial and dynamic role in regulating the flows of nutrients and materials from the watershed. In this lake zone, benthic invertebrates take an intermediary position between primary producers and microbial decomposers on one side and vertebrate predators (mainly fish) on the other side. Hence, the energy flow to the pelagic depends 
also on a well-functioning benthic energy channel from the littoral. Notably, changes in any ecosystem process are potentially reflected by related changes in the structure (abundance and species composition) of the benthic invertebrate assemblages. Hence, lake assessment based on benthic invertebrates conveys crucial information on the ecological status of a lake ecosystem which is not reflected by planktonic organisms. Moreover, benthic invertebrates mostly respond to eutrophication pressure, as phytoplankton, neglects the fact that many lakes are subject to other significant human impacts. This means that the ecological integrity of lakes cannot be assessed by solely surveying phytoplankton. Hence, an assessment system based on benthic invertebrates could effectively indicate multiple pressures. Benthic macroinvertebrates are considered as good indicators of local scale conditions, like in case of Lake Tinshu Abaya. This study was, therefore, designs to inventorize the diversity of benthic macroinvertebrate communities in the littoral zone of Lake Tinishu Abaya to assess the ecological condition of the lake, which the region has been strongly modified by human activities.

\section{Materials and Methods}

\section{Study Area}

Lake Tinshu Abaya is a small freshwater lake located in the Rift Valley nearly $160 \mathrm{~km}$ southwest of Addis Ababa, which is the capital city of Ethiopia. It located at $7^{\circ} 29^{\prime} 03.65^{\prime \prime} \mathrm{N}$, $38^{\circ} 03^{`} 17.79^{\prime \prime} \mathrm{E}$, and $1835 \mathrm{~m}$ above sea level. The lake is situated in a remote area $15 \mathrm{~km}$ from a small village in the township of Silttie. It is a shallow lake, having a surface area of 1253 ha [12], with a maximum and a mean depth of $3.7 \mathrm{~m}$ and $2.9 \mathrm{~m}$, respectively. During this study, two major perennial rivers (Rivers Dacha and Boboda) and a single outlet (River Badober) were always active. The former two rivers are relatively big. The lake has some commercially important fish species including the native Tilapia zilli and Barbus species, while Nile tilapia (Oreochromis niloticus), was stocked from the nearby Lake Ziway in 1997. The lake has nearly an oval shape (Figure 1). The lake has some commercially important fish species including the native Tilapia zilli and Barbus species, while Nile tilapia (Oreochromis niloticus), was stocked from the nearby Lake Ziway in 1997. The major phytoplankton taxa which were recorded in Lake Tinishu Abaya includes Bacillariophyceae (diatoms), (green algae), Cyanobacteria (blue-green algae), Euglenophyceae, Dinophyceae, and Cryptophyceae [13]. The zooplankton communities which were found in Lake Tinishu Abaya were the large body-sized microcrustaceans (copepods and cladocerans) and the smaller rotifers, and of whom rotifers are more diverse than the cladocerans and copepods [14].

The study of Yirga \& Brook [15] water quality assessments of Lake Tinishu Abaya for multiple designated water uses, showed that the various physicochemical factors responsible for the temporal variations in the physical, chemical and biological features of the lake were discussed and generalized that the lake water was well oxygenated, slightly warm, alkaline, contained more TSS, and EC, very turbid and low transparency. The lake water was fresh based on TDS value. Most of the inorganic nutrients were relatively higher and supports most aquatic lives. Based on the results of the study on various physicochemical factors, photosynthetic productivity and biomass of phytoplankton, Yirga \& Brook [16] concluded that the water of Lake Tinishu Abaya was chemically and biologically productive and it supports the survival of most of the aquatic lives, production of fish, and other related multidimensional uses. The lake is a source of livelihood and supports many socioeconomic activities. Irrigation, human consumption, and recreation are among others. It is also a corridor of different bird species and other microscopic organisms. Whereas this lake is critical for social welfares in one or another way, it is not given attention and totally unnoticed from limnological surveys. This may be primarily due to its remote location and having small size compared to other rift valley lakes of Ethiopia.

\section{Description of Sampling Sites}

General features of the lake were observed along with five sampling stations were defined: the lake has two feeder rivers one from the northern corner (Dacha River) and the other is on the southern corner (Bobodo River). Two of the macroinvertebrates sampling sites were in these feeder river sides (i.e., Dacha riverside site and Bobodo riverside site). River Badober is relatively a mall river which served as an outlet for the lake, particularly, when water volume increases during the rainy period. The third sampling site was found in this outlet riverside of the lake (i.e., Badober riverside site). The fourth site was found in the main gate towards the lake (i.e., Main gate side site). In this site, many shoreline modifications were carried (e.g., small irrigation, a demonstration site for seedling, water fetching, domestic waste disposal, and other related wastes). The last sampling site is considered as a Reference site. This site is in the surroundings of relatively pristine, as it is protected by the natural rim, and not suitable for agricultural activities, which protected it from impairment by human activities. The physical features of the sampling sites are summarized in Table 1.

\section{Sampling Protocol}

Benthic macroinvertebrates samples were collected from all the five predefined sampling stations (Table 1) in six sampling periods during the dry (March to May 2017) and rainy seasons (June to August 2017). The benthic macroinvertebrates were collected from the littoral (sampling depth: 0.25-0.5 m) using standardized kick sampling with a hand D-net $(28 \mathrm{~cm} \times 30 \mathrm{~cm}$ in diameter) with a horizontal transect (up to $50 \mathrm{~m}$ ) from the shore towards the lake when the lake depth less than $0.5 \mathrm{~m}$ and a diagonal transect when the lake depth greater than $0.5 \mathrm{~m}$. To maintain the consistency of sampling effort, a sample was obtained within 10 minutes at each site with 3 replicas. The collection of benthic macroinvertebrates were carried out based on Ontario Benthos Biomonitoring Network Protocol Manual [17]. The collected animals were washed and separated from sediment using 500 
$\mu \mathrm{m}$ sieves and they were stored in plastic bags, fixed with $5 \%$ formaldehyde, and transported to the Limnology Laboratory of Addis Ababa University for further analysis. In the laboratory, the macroinvertebrates were wash and sorted, and identified to the lowest possible taxonomic resolution (family level) under a stereo microscope) using keys by Edmondson [18], Gooderham \& Tysrlin [19], and Bouchard [20]. The identified macroinvetrebrates were counted and the diversity, number of individuals and distribution patterns were determined for specific metrics and correlated with various physicochemical variables. The various physicochemical parameters which were responsible for the diversity and abundance of the benthic macroinvertebrates were also measured using standardized method.

Table 1: Description of benthic sampling sites along Lake Tinishu Abaya.

\begin{tabular}{|c|c|c|}
\hline Site & GPS location & Description \\
\hline \multirow{3}{*}{$\begin{array}{l}\text { Dacha } \\
\text { riverside } \\
\text { (site 1) }\end{array}$} & N 07057' 220" & \multirow{3}{*}{$\begin{array}{l}\text { Along this site, Dacha River (feeder river for Lake Tinishu Abaya) is present in the northern bend. The Dacha } \\
\text { river carries organic matter and domestic wastes from the Gurage Highlands, and it ends up in Lake Tinishu } \\
\text { Abaya. Along the site, there is an evidence of high erosion and siltation. However, there is good coverage of } \\
\text { littoral macrophytes. The site is considered as highly impaired/disturbed. }\end{array}$} \\
\hline & E 0380.20’ 938”' & \\
\hline & $1817 \mathrm{~m}$ a.b.l & \\
\hline \multirow{3}{*}{$\begin{array}{l}\text { Bobodo } \\
\text { riverside } \\
\text { (site } 2 \text { ) }\end{array}$} & N 07055'396" & \multirow{3}{*}{$\begin{array}{l}\text { Along this site, Boboda River (feeder river for Lake Tinishu Abaya) is present in the southern bend. There is } \\
\text { high sediment-laden from the south corner via river Boboda. Along this site, seasonal crop production (e.g. } \\
\text { maize, tomato, chilli) is taken place and thus there is a high probability of organic pollution. But there is } \\
\text { relatively good coverage of littoral macrophytes. The site is considered as highly impaired/disturbed }\end{array}$} \\
\hline & E 0380 22' 237'” & \\
\hline & $1819 \mathrm{~m}$ a.s.l & \\
\hline \multirow{3}{*}{$\begin{array}{l}\text { Badober } \\
\text { riverside } \\
\text { (site 3) }\end{array}$} & N 07055'397" & \multirow{3}{*}{$\begin{array}{l}\text { Along this site, Badober River (serves as an outlet of Lake Tinishu Abaya) is present in the Northwest } \\
\text { direction. This site is usually used as grazing field for livestock. There are no aquatic macrophytes, except } \\
\text { garss cover at the site and hence the site is relatively considered as low/minimally disturbed. }\end{array}$} \\
\hline & E $038022^{\prime} 241 "$ & \\
\hline & $1821 \mathrm{~m}$ a.s.l & \\
\hline \multirow{3}{*}{$\begin{array}{c}\text { Main gate } \\
\text { side (site 4) }\end{array}$} & N 070 57'234" & \multirow{3}{*}{$\begin{array}{l}\text { This site is found in the main entrance road to get to gate Lake Tinishu Abaya. The site is an indication of high } \\
\text { shoreline modification. Different human activities are carried out. Predominantly bathing, watering cattle, car } \\
\text { washing, swimming, water fetching, and recreation among others are taken place. In the upper side of the site, } \\
\text { extensive irrigation takes place. Fertilizers and pesticides used for crop development in the watershed of this } \\
\text { site. The surrounding area has a gentle slope towards the lake which is exposed for wind and runoff erosion. } \\
\text { The site is without macrophytes and it is stony. The site is considered as highly disturbed. }\end{array}$} \\
\hline & E $038022^{\prime} 637^{\prime \prime}$ & \\
\hline & 1823 m a.s.l & \\
\hline \multirow{3}{*}{$\begin{array}{c}\text { Reference } \\
\text { (site 5) }\end{array}$} & N 070 58'234" & \multirow{3}{*}{$\begin{array}{l}\text { This sampling site is minimally affected by humans as compared to the other sites. It is protected by a natural } \\
\text { a cone shaped rim. Since the location is mountainous, domestic cattle and humans do not easily access it and } \\
\text { thus no agricultural activates are carried out and relatively organic and domestic wastes do not enter it. This } \\
\text { site is also sheltered by afforestation (e.g. Eucalyptus tree) with less shoreline modifications. Although the } \\
\text { macrophte coverate is low, the shoreline is covered by grass creating a sort of buffering system for the river. } \\
\text { The site is considered as minimal disturbed and relatively pristine. }\end{array}$} \\
\hline & E $038022^{\prime} 628^{\prime \prime}$ & \\
\hline & $1821 \mathrm{~m}$ a.s.l & \\
\hline
\end{tabular}

\section{Benthic Macroinvertebrate Diversity Metrics}

Benthic macroinvertebrate metrics measure different components of the community structure and have different ranges of sensitivity to stress. Therefore, it is recommendable to use several metrics because an integrated approach provides more assurance of a valid assessment Klemm et al., [21]. In the present study, the biotic Hilsenhoff Family-level Biotic Index (HFBI), Total number of taxa (Family level Richness), Percentage Dominant taxa (\% DT), Percentage Chironomidae (\%CHIR), Shannon Diversity Index (SDI), and Percent Ephemeroptera, Index (\% E) were applied.

\section{Hilsenhoff Family-level Biotic Index (H-FBI)}

This biotic index is calculated by multiplying the number of individuals of each family by an assigned tolerance value, summing these products and dividing by the total number of individuals Bouchard [21]. Each family is given a score between 0-10 depending on its tolerance to low dissolved oxygen level and has only been evaluated for organic pollutants Bode et al., [22]; Bouchard [20] Those taxa that are least tolerant to pollution (such as mayflies and stoneflies) are given the lowest scores of
H-FBI Mason [23]. High HFBI values are indicative of organic pollution, while low value indicative of clear-water conditions. The Hilsenhoff Family-level Biotic Index (H-FBI) was calculated as equation 6.1 below.

$$
H-F B I=\sum(X i \times \mathrm{ti}) / n
$$

Where $\mathrm{Xi}$ is a few individuals within the taxon, ti is the tolerance value of a tax on, and $\mathrm{n}$ is the total number of organisms in the sample. According to Hilsenhoff [24], HFBI values of 0-3.75 indicate excellent water quality while 3.76-4.25, 4.26-5, 5.01-5.75,5.76- 6.5, 6.51-7.25, and 7.26-10 indicate very good, good, fair, poor, poor and very poor water quality, respectively.

\section{Total Number of Taxa (TR)/Family Level Richness (RICH)}

Taxa richness is used as an indicator of habitat quality. This metric is the measure of community's diversity, number of different families found in samples of each site. Reductions in community diversity have been positively associated with various forms of environmental pollution, including nutrient loading, toxic substances, and sedimentation. Generally, taxa- 
richness increases with increasing water quality, habitat diversity, and habitat suitability [25].

\section{Percentage Dominant Taxa (\% DT)}

Percent DT is the percent contribution of the most numerous families, and measures community balance, or evenness of the distribution of individual families of the sample. A community dominated by relatively few species would indicate environmental stress. A high percent contribution by a single taxon indicates community imbalance. The index uses abundance of the numerically dominant family relative to the rest of the population as an indication of community balance, i.e., dominant taxa greater than $35 \%$ indicates poor water quality, between $25 \%$ and $35 \%$ indicates fair water quality, and less than $25 \%$ indicates good water quality.

\section{Percentage Chironomidae (\% CHIR)}

It is a diversity measure for which the percentage of chironomids from the sample is calculated. The percentage of Chironomidae tends to increase with a decrease in water quality because chironomids tend to be very tolerant of nutrient enrichment or pollution condition [4].

\section{Shannon Diversity Index (SDI)}

The SDI is a diversity index that combines taxa richness and community balance (evenness) to characterize species diversity Results

\section{Physicochemical Factors}

Table 2: Physicochemical variables at different benthic macroinvertebrate sampling sites: Temperature (oC), DO (mg/L), Turbidity (NTU), Conductivity $(\mu \mathrm{S} / \mathrm{cm})$, Nutrients $(\mu \mathrm{g} / \mathrm{L})$

\begin{tabular}{|c|c|c|c|c|c|c|c|c|c|c|}
\hline \multirow{2}{*}{ Sampling sites } & \multirow{2}{*}{ Season } & \multicolumn{9}{|c|}{ Physicochemical variables: mean values } \\
\hline & & Temp & DO & PH & Cond & Turb & $\mathrm{NO}_{2}$ & $\mathrm{NO}_{3}$ & SRP & TP \\
\hline \multirow{3}{*}{ Dacha riverside } & Dry & 25.53 & 5.99 & 7.37 & 236.33 & 161 & 0.72 & 1.12 & 0.05 & 0.43 \\
\hline & Wet & 29.3 & 5.34 & 7.3 & 210 & 196.33 & 0.94 & 1.16 & 0.61 & 1.49 \\
\hline & Mean & 27.42 & 5.67 & 7.34 & 223.17 & 179.8 & 0.8 & 1.15 & 0.33 & 0.96 \\
\hline \multirow{3}{*}{ Bobodo riverside } & Dry & 24.7 & 6.73 & 8.12 & 274 & 136.3 & 0.45 & 0.29 & 0.49 & 1.21 \\
\hline & Wet & 24 & 7.47 & 8.3 & 196.7 & 208 & 0.77 & 0.42 & 0.49 & 1.22 \\
\hline & Mean & 24.35 & 7.1 & 8.21 & 235.35 & 172.15 & 0.61 & 0.355 & 0.49 & 1.22 \\
\hline \multirow{3}{*}{ Badober riverside } & Dry & 21.7 & 7.3 & 8.26 & 172.67 & 122.83 & 0.43 & 0.93 & 0.07 & 0.55 \\
\hline & Wet & 22.85 & 7.19 & 8.22 & 184.5 & 120.75 & 0.43 & 0.88 & 0.07 & 0.53 \\
\hline & Mean & 22.28 & 7.245 & 8.24 & 178.59 & 121.79 & 0.43 & 0.91 & 0.07 & 0.54 \\
\hline \multirow{3}{*}{ Main gate side } & Dry & 24.3 & 8.24 & 8.64 & 400.33 & 70.33 & 0.83 & 1.3 & 0.62 & 1.09 \\
\hline & Wet & 23.2 & 7.39 & 8.34 & 206.17 & 207 & 1.21 & 1.26 & 0.77 & 1.66 \\
\hline & Mean & 23.75 & 7.815 & 8.49 & 303.25 & 138.67 & 1.02 & 1.28 & 0.695 & 1.38 \\
\hline \multirow{3}{*}{ Reference } & Dry & 24.8 & 9.43 & 9.02 & 995.67 & 71.67 & 0.04 & 0.03 & 0.01 & 0.03 \\
\hline & Wet & 28.06 & 7.18 & 8.34 & 199.13 & 116 & 0.18 & 0.22 & 0.04 & 0.07 \\
\hline & Mean & 26.43 & 8.305 & 8.68 & 597.4 & 93.835 & 0.11 & 0.125 & 0.025 & 0.05 \\
\hline
\end{tabular}

The results of the various physicochemical factors which were responsible for the diversity and distribution of benthic macroinvertebrates at each site are found in Table 2. There was spatial effect among the sampling sites (ANOVA; $\mathrm{p}<0.05$ ) on the in a community. The combination of abundance and richness in SDI is designed to indicate the state of the macro invertebrates' communities Rosenberg \& Resh [26]. A community with only a few taxa or with a few abundant taxa has low SDI. On the other hand, a community exhibits high diversity (high SDI) if many taxa with equal or nearly equal numbers are present. A high SDI indicates good benthic habitat and non-impacted water quality. Benthic macroinvertebrate dynamics of Lake Tinishu Abaya were also examined using the Shannon index as:

$$
H^{\prime}=\sum(n i / N) \ln (n i / N)
$$

Where $\mathrm{H}^{\prime}$ is the Shannon-Weaver diversity index, ni is the abundance of species $\mathrm{i}$, and $\mathrm{N}$ is the total number of individuals in the community.

\section{Statistical Analysis}

The relationships between the occurrence of benthic macroinvertebrates and significant physicochemical divers were analyzed using constrained Redundancy Analyses (RDA, CANOCO for Windows 4) using past software indicated by Leps \& Smilauer [27]. The spatiotemporal variation of the environmental regulations and benthic communities was analyzed using two-way analysis of variance (ANOVA). SPSS software package version 20 was used for ANOVA analysis. Statistical significance was set at $\mathrm{P}=0.05$. distribution of most of the physicochemical parameters. It can be observed from Table 2 below that high temperature $(27.42$ OC) but low dissolved oxygen $(5.67 \mathrm{mg} / \mathrm{L})$ were recorded at Dacha riverside site. On the other hand, pH (8.68) and electrical 
conductivity $(597.4 \mu \mathrm{S} / \mathrm{cm})$ were higher at the Reference site than the other sites. Turbidity was high at the two feeder riverside sites (Dacha riverside, 179.8 NTU and Bobodo riverside, 172.15 NTU) and the Main gate site (138.67 NTU). Turbidity of water was relatively low at the Reference site (93.835 NTU) and Badober riverside site (121.79 NTU). All the major inorganic nutrients considered in the present study were high at Main gate side, Dacha river side, and Bobodo river side sites. These sites were highly influenced by human activities. The different ambient inorganic nutrients were low at the Reference site coincides with the relative less anthropogenic factors. At Dacha riverside site, nitrogen nutrients $\mathrm{NO}_{3}$ was comparatively higher than the phosphorous nutrients.

However, in other sampling sites, the phosphorous families (SRP and TP) were higher than nitrogen families $\left(\mathrm{NO}_{2}\right.$ and $\mathrm{NO}_{3}$ ). Thus, most probably nitrogen was the limiting nutrient in the study lake in general, and in the sites. There was significant effect on the distribution of the various physicochemical factors between the two benthos sampling seasons $(\mathrm{P}<0.05)$. The temperature at all sampling sites was high during the period of wet season and low during the dry season. The reverse was true for dissolved oxygen by which it was high during the dry season and low during the wet season, but the difference was statistically insignificant ( $p>0.05$ ). Nearly, an equivalent amount of $\mathrm{pH}$ was observed in the two sampling seasons at all the

Table 3: Number of benthic macroinvertebrates collected from the study sites (Lake Tinishu Abaya) during this study and pollution tolerance value for each taxon given by Bouchard [7].

\begin{tabular}{|c|c|c|c|c|c|c|c|}
\hline \multirow[b]{2}{*}{ Taxa } & \multicolumn{6}{|c|}{ Sampling sites } & \multirow{2}{*}{$\begin{array}{c}\text { Tolerance } \\
\text { value }\end{array}$} \\
\hline & $\begin{array}{c}\text { Dacha } \\
\text { Riverside }\end{array}$ & $\begin{array}{c}\text { Bobodo } \\
\text { Riverside }\end{array}$ & $\begin{array}{l}\text { Badober } \\
\text { Riverside }\end{array}$ & $\begin{array}{l}\text { Maingate } \\
\text { side }\end{array}$ & $\begin{array}{l}\text { Reference } \\
\text { Site }\end{array}$ & Total & \\
\hline Ephemeroptera & 6 & 12 & 33 & 3 & 117 & 171 & \\
\hline Baetidae & 2 & 1 & 21 & 0 & 89 & 113 & 4 \\
\hline Caenidae & 4 & 11 & 12 & 3 & 28 & 58 & 7 \\
\hline Odonata & 108 & 67 & 14 & 10 & 24 & 223 & \\
\hline Libellulidae & 68 & 35 & 9 & 8 & 11 & 131 & 9 \\
\hline Ashnidae & 0 & 1 & 0 & 0 & 11 & 12 & 3 \\
\hline Coenagrionidae & 40 & 31 & 5 & 2 & 2 & 80 & 9 \\
\hline Diptera & 277 & 284 & 136 & 142 & 39 & 878 & \\
\hline Chironomidae & 258 & 281 & 108 & 121 & 33 & 801 & 8 \\
\hline Ceratopogonidae & 2 & 1 & 20 & 2 & 5 & 30 & 6 \\
\hline Psychodidae & 8 & 0 & 1 & 11 & 0 & 20 & 10 \\
\hline Tabanidae & 9 & 2 & 7 & 8 & 1 & 27 & 6 \\
\hline Hemiptera & 1287 & 462 & 237 & 206 & 354 & 2546 & \\
\hline Belestomatidae & 8 & 6 & 13 & 145 & 88 & 260 & 10 \\
\hline Corixidae & 512 & 328 & 114 & 0 & 0 & 954 & 9 \\
\hline Notonectidae & 691 & 97 & 83 & 45 & 251 & 1167 & 9 \\
\hline Naucoridae & 0 & 0 & 2 & 0 & 3 & 5 & 5 \\
\hline Gerridae & 1 & 0 & 1 & 7 & 0 & 9 & 6 \\
\hline Nepidae & 56 & 5 & 10 & 7 & 1 & 79 & 8 \\
\hline Mesovellidae & 16 & 26 & 14 & 0 & 2 & 58 & 8 \\
\hline
\end{tabular}

sampling sites. Electrical conductivity and water turbidity were significantly varied between the sampling seasons $(\mathrm{p}<0.05)$. The former was high at the dry season and the latter was high during the wet season. Compared to the two-sampling season, the water turbidity of the lake at all sampling sites was higher during the wet season than the dry season.

\section{Diversity of Benthic Macro Invertebrates}

In the present study, a total of 5735 benthic macroinvertebrate specimens comprising of 23 taxa were collected from all the study sites. The number of benthic individuals significantly varied among the sampling sites (ANOVA test; $\mathrm{p}<0.05$ ). It was high at Dacha riverside $(\mathrm{n}=2089)$ followed by Bobodo riverside $(\mathrm{n}=$ 1145), Reference sites ( $n=963)$, Badober riverside $(n=859)$, and Maingate side $(n=679)$ (Table 3$)$. There was significant seasonal difference in the number of counted benthic individuals between the two seasons $(\mathrm{P}<0.05)$. Higher number of benthic individuals were collected in the wet season $(n=3583,62.5 \%)$ than dry season $(n=2152,37.5 \%)$. The Hemiptera Families were the predominant taxa that contributed the largest number $(n=2546$, $44.39 \%)$ of the total samples followed by the Diptera $(n=878$, $15.31 \%)$, Coleoptera $(n=835,14.56 \%)$, and the Gastropoda $(n=631,11 \%)$. On the other hand, the Ephemeroptera $(n=171$, $2.98 \%)$, Hirudinae $(n=335,5.84 \%)$, and Oligochates $(n=116$, $2.02 \%$ ) were represented by relatively low number of specimens (Table 3). 


\section{Oceanography \& Fisheries Open access Journal}

\begin{tabular}{|c|c|c|c|c|c|c|c|}
\hline Coleoptera & 146 & 128 & 181 & 106 & 274 & 835 & 47 \\
\hline Dytiscidae & 8 & 17 & 56 & 1 & 429 & 5 \\
\hline Hydrophildae & 138 & 110 & 80 & 105 & 170 & 603 & 5 \\
\hline Gyrinidae & 0 & 0 & 24 & 0 & 38 & 62 & 4 \\
\hline Elimidae & 0 & 1 & 21 & 0 & 19 & 41 & 5 \\
\hline Gastropoda & 152 & 82 & 201 & 61 & 135 & 631 & 7 \\
\hline Hirudinae & 78 & 86 & 47 & 110 & 14 & 335 & 10 \\
\hline Oligochates & 35 & 24 & 10 & 41 & 6 & 116 & 8 \\
\hline Total individual & 2089 & 1145 & 859 & 679 & 963 & 5735 & \\
\hline Number of taxa & 19 & 19 & 22 & 16 & 20 & & \\
\hline
\end{tabular}

The major components of the benthic taxa were the Notonectidae $(n=1167)$, Corixida $(n=954)$, and the red Chironomidae $(n=801)$. The Baetidae $(n=113)$, Libellulidae $(n=131)$, Dytiscidae $(n=129)$, and Belestomatidae $(n=260)$ were comparatively represented by high number of individuals. All the remaining taxa were low ( $<100$ individuals). The Elimidae, Ceratopogonidae $(n=41)$, Tabanidae $(n=30)$, and Psychodidae $(n=20)$ taxa were represented by low number of animals. Ashnidae, Gerridae, and Naucoridae were the minor components $(<0.5 \%)$ of the benthos communities and collected only a total of 12,9 , and 5 individuals, respectively (Table 3). In Lake Tinishu Abaya, majority (70\%) of the benthic composition was pollution tolerant taxa. The presence of pollution sensitive group (Ephemeroptera) in all the sampling sites were too low $(<30 \%)$. Among the EPT group (Ephemeroptera, Plecoptera, and Trichoptera), only Ephemeroptera families (Baetidae and Caenidae) was found in Lake Tinishu Abaya. The attributions of this pollution sensitive taxa, Ephemeroptera, varied significantly among the sampling sites and between the study seasons $(p<0.05)$. This group was over dominated at the Reference site. Comparing the two sampling seasons, the number Ephemeroptera specimen was high during the dry period than the rainy period.

\section{Environmental Regulations and Benthic Communities}

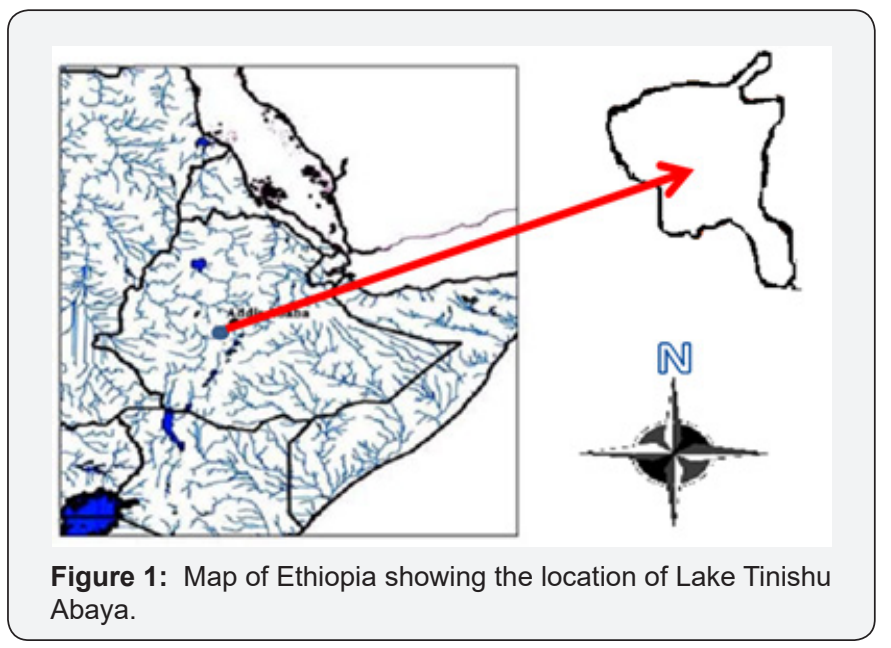

The correlation of the various environmental parameters and benthic macroinvertebrates occurrence and abundance was analyzed using constrained Redundancy Analyses (RDA graph)
(Figure 2) (Table 4). In the RDA graph, the first and second axes together explained $94.5 \%$ of the cumulative percentage variance of species environment relation. The first axis and second axis explained $76.9 \%$ and $16.5 \%$ of the species environment relation, respectively (Table 4). As indicated in RDA graph in figure 1 below, most of the inorganic nutrients were concentrated at the Bobodo riverside site. The site is an area of high sedimentation and siltation through runoff via Bobodo River from the southern corner. The occurrence of both phosphorous nutrients (SRP \& TP) and nitrogen nutrients $\left(\mathrm{NO}_{2} \& \mathrm{NO}_{3}\right)$, and water turbidity were correlated positively and significantly with axis 1 . On the other hand, DO, pH, and electrical conductivity were found to correlate positively and significantly with axis 2 . Water temperature at each sampling site correlated positively and strongly with axis 1. As shown in Figure 2, temperature and dissolved oxygen were correlated in the opposite direction.

Table 4: Summary of the statistics of the DA diagram.

\begin{tabular}{|c|c|c|c|c|}
\hline Axes & $\mathbf{1}$ & $\mathbf{2}$ & $\mathbf{3}$ & $\mathbf{4}$ \\
\hline Eigenvalues: & 0.769 & 0.176 & 0.043 & 0.012 \\
\hline $\begin{array}{c}\text { Species-environment } \\
\text { correlations: }\end{array}$ & 1 & 1 & 1 & 1 \\
\hline $\begin{array}{c}\text { Cumulative percentage } \\
\text { variance of species data: }\end{array}$ & 76.9 & 94.5 & 98.8 & 100 \\
\hline $\begin{array}{c}\text { of species-environment } \\
\text { relation: }\end{array}$ & 76.9 & 94.5 & 98.8 & 100 \\
\hline
\end{tabular}

At the Reference site, electrical conductivity did seem to strongly control the occurrence of benthic taxa. In addition, $\mathrm{pH}$ and DO were an important factor for the abundance of benthic taxa at the reference site. In the study, temperature was the prominent regulators for the abundance of benthic communities at Dacha riverside site relative to the other parameters; but still, inorganic nutrients were also important factors at this site (Figure 1). On the other hand, $\mathrm{pH}$ and $\mathrm{DO}$ were major regulators for the occurrence as well as abundance of benthic macroinvertebrates at Main gate and Bobodo riverside sites (Figure 2). In all the sampling sites, the occurrence of pollution sensitive taxa was low. The most sensitive taxa having low tolerance value (Table 3) reported in the study lake were Ashnidae (tolerance value=3), Baetidae (tolerance value $=4$ ), and Gyrinidae (tolerance value=4). Naucoridae, Dytiscidae, Hydrophildae, and Elimidae benthic taxa are a moderately pollution tolerant taxon (tolerance 
value $=5$ ) that were recorded in the study area. All these pollution sensitive groups account $30 \%$ of the total number of benthic taxa in Lake Tinishu Abaya. The occurrence of sensitive taxa (Ashnidae, Baetidae, and Gyrinidae) and moderately tolerant taxa (Naucoridae, Dytiscidae, Hydrophildae, and Elimidae) correlated positively and strongly with electrical conductivity, dissolved oxygen, and pH. However, they correlated negatively with most of the inorganic nutrients (Figure 2). All these taxa were concentrated at the Reference site concurrently with minimal human induced factors.

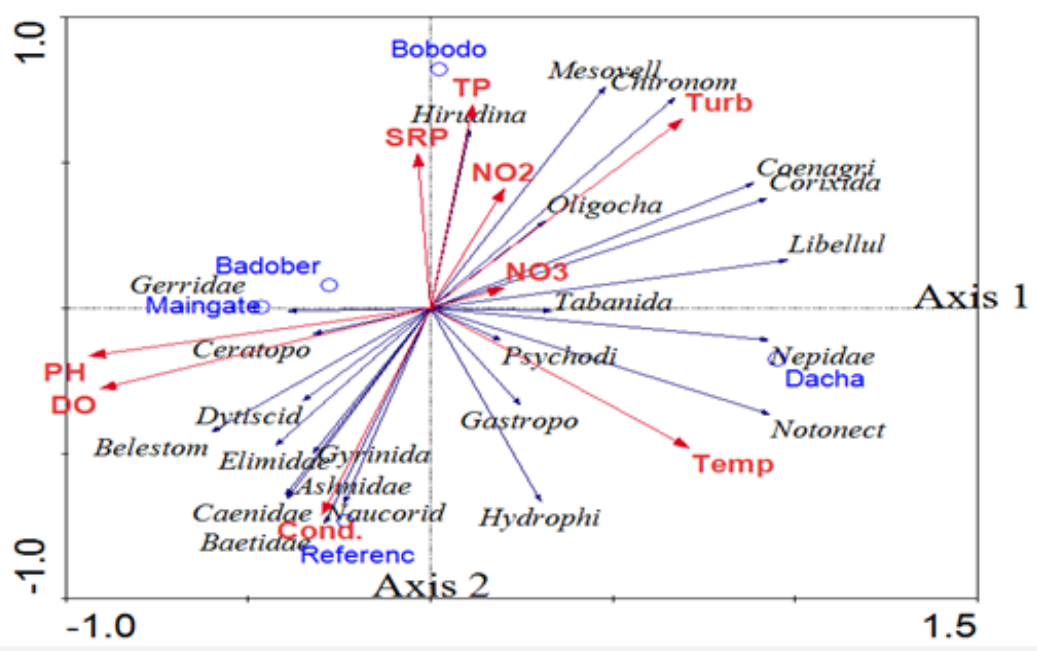

Figure 2: Tri-plot of the constrained Redundancy Analyses (RDA, CANOCO for Windows 4) for benthic macro invertebretaes taxa (blue arrows) and environmental variables (red arrows) at each sampling sites (Blueprint). Mesovell-Mesovellidae, Hirudina-Hirudinae, ChironomChironomidae, Oligocha-Oligochates, Coenagri-Coenagrionidae, Corixida-Corixidae, Libellul-Libellulidae, Tabanida-Tabanidae, GyrinidaGyrinidae, Ceratopo-Ceratopogonidae, Dytiscid-Dytiscidae, Belestom-Belestomatidae, Naucoridae-Naucoridae, Notonect-Notonectidae, Gastropo-Gastropoda, Hydrophi-Hydrophildae, Psychodi-Psychodidae

Hirudinae and Oligochates are pollution tolerant taxa having a tolerant value of 10 and 7 , respectively (Table 3 ). The occurrence of Hirudinae correlated positively with the phosphorous nutrients (SRP \& TP) while the Oligochates correlated positively with the nitrogen nutrients $\left(\mathrm{NO}_{2}\right.$ and $\left.\mathrm{NO}_{3}\right)$. The occurrence of these taxa was high at Bobodo riverside site coincides with high water turbidity. The other high pollution tolerant taxa found in the sampling site were Coenagrionidae, Corixidae, and Libellulidae. All these species had similar pollution tolerance value, which is 9 (Table 3). The occurrence of all the three tolerant taxa (Coenagrionidae, Corixidae, and Libellulidae) correlated positively and strongly with turbidity and $\mathrm{NO}_{3}$. The red blooded Chironomidae and Mesovellidae are considered as high pollution tolerant taxa (tolerant value=8) (Table 3). The occurrence of these two pollution tolerant taxa correlated positively and significantly with water turbidity (Figure 1) and thus water turbidity seemed to be the possible reason for the occurrence as well as abundance of the Chironomidae and Mesovellidae. On the other hand, $\mathrm{pH}$ and DO seemed to influence the ecology of Belestomatidae and Ceratopogonidae taxa. Both taxa are pollution tolerant taxa, but the former is high pollution tolerant (10), while the latter is moderate (6) (Table 3). The occurrence of Gerridae (tolerance value =6) correlated negatively with most of the inorganic nutrients and this taxon was found high at the main gate side site (Figure 2). In Lake Tinishu Abaya, Notonectidae (Backswimmers) were widely dominated the abundance of benthos specimens. This predominant taxon correlated positively and strongly with temperature, water turbidity, and nitrogen nutrient $\left(\mathrm{NO}_{3}\right)$. Notonectidae was preferable at Dacha riverside site coincides with high temperature and water turbidity.

\section{Benthic Macroinvertebrate Diversity Metrics}

\section{Taxa Richness (TR)}

Table 5: Different benthic metrics at the sampling sites in Lake Tinishu Abaya.

\begin{tabular}{|c|c|c|c|c|c|c|}
\hline \multirow{2}{*}{$\begin{array}{c}\text { Sampling } \\
\text { sites }\end{array}$} & \multicolumn{5}{|c|}{ Benthic Macroinvertebrate Diversity Metrics } \\
\cline { 2 - 7 } & \% TR & \% DT & \% E & \% CHIR & \% HFBI & SDI \\
\hline $\begin{array}{c}\text { Dacha } \\
\text { riverside }\end{array}$ & 82.61 & 61.6 & 0.29 & 12.35 & 8.4 & 1.97 \\
\hline $\begin{array}{c}\text { Bobodo } \\
\text { riverside }\end{array}$ & 82.61 & 40.3 & 1.05 & 24.54 & 8.42 & 2.086 \\
\hline $\begin{array}{c}\text { Badober } \\
\text { riverside }\end{array}$ & 95.65 & 27.6 & 3.84 & 12.57 & 7.3 & 2.462 \\
\hline $\begin{array}{c}\text { Maingate } \\
\text { side }\end{array}$ & 69.57 & 30.3 & 0.44 & 17.87 & 8.2 & 2.123 \\
\hline $\begin{array}{c}\text { Reference } \\
\text { site }\end{array}$ & 86.96 & 36.8 & 12.15 & 3.43 & 6.9 & 2.234 \\
\hline
\end{tabular}

In the present study, different macroinvertebtate diversity metrics were used (Table 5). In the study lake, there was not spatial effect on the distribution of the total number of taxa among the sampling sites (ANOVA test; $p$ the total number of taxa was relatively high at a relatively minimal human impact sites (Badober riverside and Reference site) compared to that of high impaired site (Dacha riverside, 
Bobodo riverside, and Main gate sites). The total number of taxa comprised at the study sites was high (22 taxa) at the Badober riverside site, intermediate (20 taxa) at reference site, and low (19 taxa) at Dacha riverside and Bobodo riverside sites (Table 5). Although statistically insignificant ( $p>0.05)$, the value of percent taxa richness (\%TR) varies among sampling sites. The value of this metric ranged from low value of $69.57 \%$ at Main gate site to a high value of $95.65 \%$ at Badober riverside site (Table 5).

Shannon Diversity Index (SDI) and Percentage Dominant taxa (\% DT)

The Shannon Diversity Index was significantly varying among sampling sites $(\mathrm{P}<0.05)$. The value of SDI was high (2.462) at Badober riverside with low (27.6\%) \%DT and low (1.97) at Dacha riverside site corresponding to high (61.6\%) \%DT (Figure 3). The Reference site had higher (2.234) SDI than Bobodo riverside site (2.086) and Maingate side site (2.123). In most cases, the SDI) and \%DT were inversely correlated (Figure 2 ). The distribution of \%DT was appreciably differences among sampling sites. It was high at Dacha riverside (61.6\%) and low (27.6\%) at Badober riverside (27.6\%) (Table 3).

\section{Percentage Chironomidae (\%CHIR)}

The large abundance of chironomidae is an indication of organic pollution and nutrient enrichment. In the present study, percentage of chironomidae considerably varied among sampling sites. The lower (3.45\%) and upper (25.54\%) values of this metrics were found at the Reference site and Bobodo riverside site, respectively. Except the reference site, generally, high percent chironomidae was observed in the remaining sampling sites corresponding with $17.8 \%, 12.35 \%$, and $12.57 \%$ at Maingate side, Dacha riverside, and Badober riverside sites, respectively indicating the sites were environmental stressed.

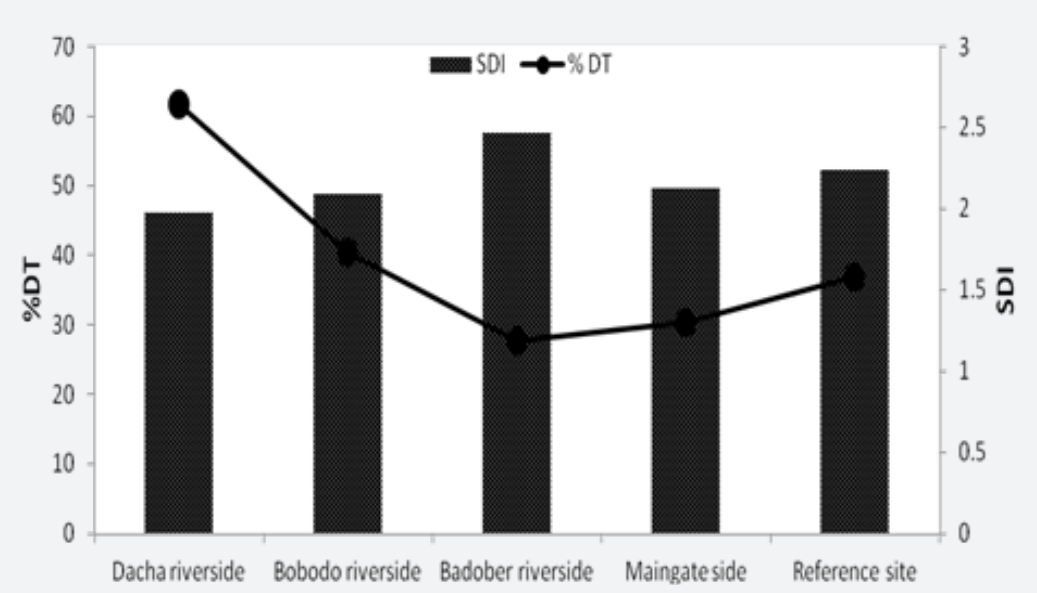

Figure 3: Spatial distribution of the Shannon Diversity Index (SDI) and Percentage Dominant Taxa (\% DT) at sampling sites in Lake Tinishu Abaya.

\section{Percentage Ephemeroptera (\% E)}

Organisms in the Ephemeroptera, Plecoptera, and Trichoptera (EPT) groups are pollution sensitive and qualified as indicators of good water quality. In this study, Plecoptera and Trichoptera were not found. It was only Ephemeroptera families reported (Table 3). However, the presence of Ephemeroptera in the study lake was, generally, low. The distribution of \% $\mathrm{E}$ varied notably among sampling sites and between seasons. The percentage of Ephemeroptera was higher (12.15\%) at the Reference site. Compared to the Reference site, the percentage of Ephemeroptera was low in the other sites, having values of $0.29 \%, 0.44 \%, 1.05 \%, 3.84 \%$, at Dacha riverside, Maingate side, Bobodo riverside, Badober riverside sites, respectively (Table 5).

\section{Hilsenhoff Family-level Biotic Index}

In the study area, the Modified Family Biotic Index (FBI) was developed to detect the presence of organic pollution. In this study, almost all the sampling sites showed higher FBI values; suggesting comparatively low water quality. The value of HFBI ranged from 6.90 to 8.40 . The value of this metrics was high at the Bobodo and Dacha riverside sites. The lowest value of this metrics was recorded at the Reference site (Table 5) indicating the site is relatively good water quality.

\section{Discussion}

\section{Physicochemical Regulations}

The various physical, chemical, and inorganic nutrients regulations responsible for the diversity and abundance of benthic invertebrates in the present study sites are analyzed (Table 2). It is observed from the results that, except dissolved oxygen, other physicochemical parameters are noticeably high at all sampling sites. The presence of considerably high levels of DO, pH and other physical parameters seems to support the survival of most of the benthic invertebrate communities in Lake Tinishu Abaya. The distribution of most of the chemical and physical parameters varied significantly among the sampling sites. The water turbidity and all inorganic nutrients are high at the impacted sites (Dacha riverside, Bobodo riverside, and Main 
gate side). On the other hand, the presence of dissolved oxygen, $\mathrm{pH}$, and electrical conductivity are high relatively at minimal impacted sites (Reference site and Badober riverside).

Dissolved oxygen is an important parameter that determines the spatial and temporal distribution of aquatic organisms as this is essential for their respiration [28,29]. In the present study, compared to other physical parameters, dissolved oxygen was low at most of the sampling sites. This is ultimately because of the presence of relatively high temperature al the study sites. The RDA graph (Figure1) shows temperature and dissolved oxygen correlated negatively and strongly. More dissolved oxygen is present in water with a lower temperature compared to water with a higher temperature Peeters et al. [30]. The reason for this invers's relationship between dissolved oxygen and temperature is that the solubility of a gas in a liquid is an equilibrium phenomenon Bachmann et al. [31] considered that whereas wind is a major oxygenator in large lakes, dissolved oxygen in smaller lakes is largely determined by photosynthetic action of phytoplankton and complete oxygen depletion was not observed, apparently because of significant water movement through the lake as a result of mass water movement due to frequent wind induced top-down mixing. A similar fact was observed in all sampling sites of the present study since oxygen was not completely depleted. This owes to the polymictic nature of the Lake Tinishu Abaya. The non-complete depletion of oxygen in all the sampling sites may lead to the existence of various types of benthic macroinvertebrates in the study area.

Water temperature has been recognized as a major factor in the distribution, abundance and richness of aquatic organisms in general and benthic communities. Temperature also controls the dynamics of sustainability and survivorship of various aquatic organisms that live in lakes though different life forms have a recommended temperature variety. Temperature affects the physiological processes of organisms, so temperature dynamics may change life cycle patterns and trophic interactions [32]. The higher the water temperature, the greater the biogeochemical activity influenced by the environmental intrinsic and extrinsic parameters. In this study, a considerable high temperature has recorded at all sampling sites. The presence of this marked high temperature might have induced higher metabolic processes in DO rich environment and hence high proliferation of or occurrence of high benthic organisms in the study sites.

Two main aspects of the climatic impacts on streams are water temperature and water low (Du-rance \& Ormerod 2007, 2009). Temperature has been long recognized as a major factor in the distribution, abundance and richness of aquatic organisms along the gradients in latitude and altitude (Vannote et al.

1980, Ward 1992). Water temperature is also impor-tant for the embryonic development, larval growth,

emergence, metabolism, and survivorship of aquatic organisms (Ward 1992, Haidekker \& Hering 2008)
All winter biotic metrics decreased associated with the water temperature increase in this study (confirming the first study objective). The reduction in the community composition in relation to temperature increase is real and may result in winter macroinvertebrate abundance declines of $11.1 \%$ for every $1{ }^{\circ} \mathrm{C}$ water temperature rises in the study streams. Higher losses $(21$ $\%$ ) were predicted for stream macroinvertebrates during spring in British Llyn Brianne River (Durance \& Ormerod 2007).

Other important physical parameters considered for the regulations of benthic macroinvertebrates abundance and diversity in the present study are $\mathrm{pH}$ and electrical conductivity. The variation in the $\mathrm{pH}$ could have effect in the biodiversity and richness [33]. Acidification has severely impacted freshwater resources [34]. Experiments conducted at a range of spatial scales, from laboratory experiments to whole-stream manipulations, demonstrate adverse effects of acidic $\mathrm{pH}$ on benthic invertebrate communities and differences in sensitivity among aquatic insects. In the present investigation, the values of $\mathrm{pH}$ show that the water of all the sampling sites are alkaline and no acidification has been observed since $\mathrm{pH}$ is always greater than 7 . The absence of acidic conditions in the study area may elucidate the occurrence of diverse types of macro invertebrates in large numbers (Table 3) (Figure 2).

There were not remarkable differences of $\mathrm{pH}$ among the sampling site. But it was the high at the Reference site corresponding to low human perturbation and low at Dacha riverside site where high human perturbations. A relatively higher mean value of $\mathrm{pH}$ has been observed during dry period compared to wet period. The decrease in $\mathrm{pH}$ values during the periods of rainy season owes to the dilution caused by the rainwater and may be the results of the production of $\mathrm{CO} 2$ from increased biological oxidation and photosynthetic processes of aquatic plants that may have ultimately contributed to the reduction of pH Melack [35]. Electrical conductivity is a good measure of salinity in water. It has long been considered an important factor in determining aquatic macroinvertebrate fauna in lentic as well as lotic systems [6]. An understanding of the effect of conductivity or salinity on aquatic fauna has considerable theoretical and practical implications [36].

In the present study, relatively high electrical conductivity has noticed at all sites. The distributions of these ionic concentrations have gone from high values at the minimal impacted site (Reference site) to low values at high impacted sites (Dacha riverside and Bobodo riverside). This decline of electrical conductivity in rainy season may be due to the dilution of water as a result of increasing water level via the feeder Rivers Dacha and Boboda. Generally, the presence of relatively high level of conductivity clearly indicated that water in the study areas considerably ionized and has the higher level of ionic concentration activity due to excessive dissolved solids. This might have been supported the survival of most of the benthic macroinvertebrate communities in Lake Tinishu Abaya. 
Shallow lakes, in general, can occur in two alternative stable states, a clear-water state, and a turbid state [37]. Lake Tinishu Abaya is turbid state (chapter 2). The same is true for the sampling sites of benthic macroinvertebrates that is high turbidity had noticed in all the study sites. One of the plausible reasons for the occurrence of high turbidity is the entrance of high sediment laden from agricultural area through runoff via the Feeder Rivers. The two Feeder Rivers, namely, Dacha and Bobodo are active during the sampling period main in the rainy months of July and August. These rivers carry complex types of sediments and garbage from the Guragae highlands where large settlements and towns such as Worabie to end up in Lake Tinishu Abaya. The best-known adverse consequence of agriculture on watersheds is the large amount of sediment exported into adjacent rivers and streams [38]. Sedimentation in aquatic ecosystems is generally accompanied by deterioration of water quality, reduced light penetration, and the filling of interstitial spaces in benthic substrates [3]. During the present study, high agricultural activities are underway. The lake generally has no any buffer zone. The agricultural activities that exposed the topsoil have promoted the transport of sediments that directly end up in Lake Tinishu Abaya. This all affect the diversity as well as abundance of benthic communities in the study lake.

Streambed degradation by sedimentation can ultimately result in the extinction of benthic macroinvertebrates [39] because these organisms predominantly dwell on stream substrates and require specific geomorphological structures for completion of oviposition and other life cycle stages [40]. Thus, the overall success of diverse benthic macroinvertebrate communities is strongly dependent on the integrity of their physical environments [41]. Different studies have documented multiple adverse effects of sedimentation on benthic macroinvertebrates such as decline in species diversity and density reduction in the number of suitable habitats, declines in food resources and food quality, reduction in feeding and respiration [42], and increases in drifting rates of the organisms.

The major inorganic nutrients occurred in appreciable proportions in the present study sites are nitrogen (NO2 and NO3) and phosphorous nutrients (SRP and TP). In all the sampling sites, all these nutrients are considered as the preeminent regulating factors for the diversity as well as abundance of benthic communities. All the nutrients measured during the study were relatively high at each sampling sites that support the existence of different invertebrate taxa. There were significant variations in the concentration of nutrients among the study sites. Both the nitrogen and phosphorous nutrients were considerably high at the Main gate site concurrently low benthic macroinvertebrate. During the study time, different anthropogenic activities were observed at the Main gate site. The various anthropogenic activities are believed to be the main sources of high nitrogen and phosphorous nutrients, in turn, resulting in high eutrophication of the site which affected the survival of benthic macro invertebrates at this site.
Cultural eutrophication from nutrient enrichment is a globally recognized important anthropogenic impact on aquatic ecosystems [43]. Despite this, current understanding of its effects on benthic assemblages remains poor, particularly in lakes [44]. This owes largely to their high spatiotemporal variability at scales among and within both lakes and habitats [45]. The negative effects of nutrient enrichment are, however, arguably manifested most strongly in the benthic zone owing to decreased oxygen availability [46] and reduction of phytobenthic production [47] and structural complexity. There were markedly clear variations in the changes on benthic abundance along nitrogen and phosphorus gradient among sampling sites. Some invertebrate taxa were less pronounced on nutrient poor sites (Reference site and Badober riverside site). For instance, Ephemeroptera showed significant declines with nutrient enrichment. Redundancy Analyses (RDA) graph (Figure 2) also revealed a clear distinction in taxonomic composition as well as abundance between Reference sites (non-nutrient enriches site) and other nutrient enriched sites.

\section{Diversity of Benthic Macroinvertebrates}

Diversity values for real communities are often found to fall between 1.0 and 6.0. Staub et al. [48], had also set diversity index less than 1 for poor diversity, 1-2 moderate diversity, $2<3$ for average diversity and $>3$ for high diversity. Based on the value of Shannon index, Dacha riverside site is moderately diversified whereas all the remaining sampling sites are diversified on average. In general, considering the Shannon Diversity Index considered among study sites, the diversity of benthic macroinvertebrates in Lake Tinishu Abaya is bounded from moderate to average diversity of benthic macroinvertebrate communities. The occurrence of this average diversity of the benthos in the study area might be due to the existence of good coverage of aquatic macrophytes at the littoral area of the most of the sampling sites, presence of high level of ambient inorganic nutrients, relatively high water temperature, the alkaline nature of the lake, and possibly the weathering condition of the surrounding area.

Shannon Diversity Index $\left(\mathrm{H}^{\prime}\right)$ decreased as the perturbation increased [49]. According to the study by there are 3 classes of pollution status based on $\mathrm{H}^{\prime}$. In their scale, water bodies with $\mathrm{H}^{\prime}$ value of more than 3 has no contaminant, $\mathrm{H}^{\prime}$ values ranging from 1-3 contain moderate contaminants and $\mathrm{H}^{\prime}<1$ indicates high pollution level. In Lake Tinishu Abaya, the $\mathrm{H}^{\prime}$ of benthic macroinvertebrate ranged from 1.97 at Dacha riverside site to 2.462 at Bobodo riverside site; indicating that all the sampling sites are moderately polluted. This leads to the inference that Lake Tinishu Abaya is moderately polluted in according to the values of Shannon Diversity Index. Different shoreline modifications (crop cultivations, irrigation farms, disposal of wastes, sedimentation, and siltation) on the watershed area of lake have been observed during the meantime of this study. These resulted in the high rate of organic pollutions [50]. 
In the study area, the number of benthic macroinvertebrate taxa or richness is comparatively similar among the sites and the changes do not have any meaningful differences among them but the composition of each taxon with their tolerance value among sites tells a lot about the impacts stated that sites with greater than 26 taxa as non-impacted, 19-26 as slightly impacted, 11-18 as moderately impacted and $0-10$ as severely impacted. Based on this criterion, all the sampling sites considered in the present study (Table 5), fall in slightly impacted range [51]. Considering the total number of benthic macroinvertebrates taxa (19-23) that have been observed from all sampling sites, the ecological condition of Lake Tinishu Abaya, in general, is slightly impacted as a result of different human perturbations such as irrigation activities at the near shore area, bathing and washing, release waste, and other related possible suggestions [52].

The total number of benthic individuals was considerably different among the study sites. The presence of this remarkable differences in the abundance of benthic communities among the study sites is thus, because of differences in the various physicochemical regulations (RDA graph (Figure 2) and because of the differences in the coverage of aquatic macrophytes. The largest number of invertebrate communities was recorded at Dacha and Bobodo riverside sites concurrently with high level of all types of inorganic nutrients, high temperature, and increasing water turbidity [53]. During this study, relatively good coverage of aquatic macrophytes has been observed at Dacha and Bobodo riverside sites. This ultimately resulted in the high number of specimens at the two indicated sites. Compared to the two sampling seasons, high number of specimens has been recorded during the wet season than dry season [54]. The difference in water temperature between the two sampling seasons results the seasonal variations in the number of benthic individuals. The seasonal difference in the number of benthic individuals may be also the significant difference in habitat coverage between the two seasons. During the time of data collection, it was observed that the littoral macrophytes were condensed during the rainy time. Cyperus dubius and Persicaria senegalensis, and Potamogeton species were dominant the littoral region of the lake during the rainy season (June-August). However, all the larger macrophytes were totally discarded in most of the dry season (January-April).

In Lake Tinishu Abaya, Hemiptera (true bugs) particularly, Notonectidae and Corixida are predominant taxa that reprented the largest number of benthic specimens [55]. Hemipterans are relatively tolerant of many forms of pollution. Surface dwellers have very little physical connection with water and therefore are less dependent on the water quality [19]. This feature of Hemiptera might have resulted in their wide dominance of the study areas. The Notonectidae or commonly called Backswimmers is extensible dominated the number of benthic individuals. Backswimmers can fly easily and can, therefore, colonize new wetlands quite quickly. They are very active predators feeding on a mixture of invertebrates from the open water and the water surface. Their ability to colonizing new environments and feeding from open water and the surface with predating behaviors might have facilitated the presence of high number of individuals in the study area [56]. Notonectidae is correlated strongly and positively with water temperature (RDA graph in Figure 2). The presence of high temperature is likely the cause for the existence of high abundance of the Notonectidae than other benthic individuals in Lake Tinishu Abaya [57].

Diptera families the red Chironomidae (non-biting midges), are other important benthic invertebrates that are comprised of large number of specimen next to the Hemiptera in the study sites. The extreme variability of dipterans extends to their tolerance to pollution. Some of the animals among the dipterans prefer organically polluted sites and thrive in sewage and carrion [58]. The same plausible reason has given for the dominance of Diptera in general and the high abundance of Chironomidae for the present study sites. Diverse and well-studied families such as the Chironomidae can provide much information about their surrounding environment. Different species are often indicative of different environmental conditions such as water chemistry. Sometimes these changes also indicate environmental impacts. In extreme cases of pollution, the deformities of the more tolerant species can be studied to assess environmental impacts.

At the high impacted sampling site, pollution tolerant taxa have dominated the total specimen. Notonectidae, Chironomidae, and Belestomatidae taxa are high pollution tolerance (8-10) (Table 3). The Notonectidae, Chironomidae, and Belestomatidae are the dominant benthic taxa at Dacha rivers side, Bobodo riverside, and Main gate side sites. All these sites are highly modified with shoreline modification. The high percentage of a single or some common taxa at the impacted sites, particularly at Dacha and Bobodo riverside sites might be due due to instability of the area by the inflow of rivers Dacha and Bobodo runoff. However, point out some unstressed habitats are dominated by only a few taxa due to habitat, flow, and seasonal effects. The better stability in Badober and Reference site promoted the low percentage dominance; moreover, promoted the relative high number of sensitive group than the tolerant ones, indicating water quality of the site.

According to Barbour et al. [25], percent dominant taxa (\%DT) greater than 45 indicate impaired, 40-45 possible impaired and less than 40 unimpaired conditions. Based on this classification, \% TD at Dacha riverside site is greater than 40 indicating impaired site, at Bobodo riverside site is within 4045 indicating possible impaired site. \%DT at Badober riverside and Reference sites is less than 40 indicating the two sites are unimpaired condition (Table 3). The presence or absence of certain taxa is related to water quality rather than other ecological factors. According to Hilsenhoff [24], the presence of pollution sensitive groups rather than pollution tolerant groups can indicate water quality because pollution tolerant groups can 
inhabit both habitats according to their niche preference. During the present study, the benthic community is broadly dominated by pollution tolerant taxa compared to pollution sensitive taxa. This clearly indicates the low water quality of Lake Tinishu Abaya in general, and all sampling sites in relation to benthic macroinvertebrate assemblages.

The presence of pollution sensitive group significantly varied among sampling sites. It is commonly found at Reference site. Compared to the two sampling seasons, the pollution sensitive group is low during the rainy period. During the rainy season, high organic pollution from the watershed entered to the littoral region of the lake through runoff. This resulted in the high occurrence of organic pollution. Since pollution sensitive groups has low pollution tolerance, low number of specimens have been reported during the wet season than in the dry one. The percentage composition of high pollution tolerant communities such as Gastropoda, Odonata, Diptera, Hirudinae (Leeches), and Oligochates (the aquatic earthworm) are high at the Dacha riverside, Bobodo riverside and Main gate side sites which happened to be of high human interference sites. The presence of significant number or, percentage of chironomidae in the study lake, shows the existence of organic pollution that resulted in less water quality that indicating that the lake was under long term environmental stress.

Hilsenhoff Family Biotic Index (HFBI) is used to detect organic pollution. All study sites considered in this study, showed relatively high FBI values; suggesting low water quality. Lower FBI was calculated at Reference site; suggesting comparatively higher water quality and high FBI was estimated at Badober riverside site and Dacha riverside site; suggesting comparatively low water quality. As noted, HFBI values of 0-3.75 indicate excellent water quality. HFBI values of 3.76-4.25, 4.26-5, 5.015.75,5.76- 6.5, 6.51-7.25, and 7.26-10 indicate very good, good, fair, poor, poor and very poor water quality, respectively. In this study, the HFBI value at Reference site represented poor water quality while the values at all the other sites represented very poor water quality in relation to HFBI.

\section{Conclusion}

Tilapia zilli To conclude, the use of benthic macroinvertebrates in the study is an important aspect for the jugment of the water condition of the study area. Based on the results of benthic macroinvertebrate assemblages and their dynamics, the existence of organic pollution is evident. This is an indication that Lake Tinishu Abaya has undergone long term environmental stress. This obviously calls for participatory and interdisciplinary actions of watershed management and wise use of aquatic resources with compliance to commonly set agenda of sustainable use of natural resources.

\section{Acknowledgment}

The authors thank the Department of Zoological Sciences of Addis Ababa University for assisting with laboratory facilities.
Bureau of Cultural and Tourism for Selttie Woreda (Ethiopia) is also appreciated for allowing the study to be conducted in the area.

\section{References}

1. Washington HG (1984) Diversity, biotic and similarity indices. Wat Res 18: 653-694.

2. Samal NR, Mazumdar A, Johnk KD and Peeters F (2009) Assessment of ecosystem health of tropical shallow waterbodies in eastern India using turbulence model. Journal of Aquatic Ecosytems Health Management Society 12: 215-225.

3. Cretaz AL and Barten PK (2007) Land use effects on stream flow and water quality in the northeastern United States. In: CRC Press, Boca Raton, Florida, US, pp. 319.

4. Burgmer T, Hillebrand $\mathrm{H}$ and Pfenninger $\mathrm{M}$ (2007) Effects of climate-driven temperature changes on the diversity of freshwater macroinvertebrates. Oecologia 151: 93-103.

5. Plafkin JL, Barbour MT, Porter KD, Gross SK, Hughes RM (1989) Rapid Bioassessment Protocols for Use in Streams and Rivers: benthic macroinvertebrate and fish. US EPA 444/4-89-001, Washington, US.

6. Mathi BJ and Dorris TC (1968) Community structure of benthic macroinvertebrates in an intermittent stream receiving oil field brines. The American Midland Naturalist. 80: 428-439.

7. Bonada N, Dallas H, Rieradevall M, Prat N and Day J (2006a) A comparison of rapid bioassessment protocols used in 2 regions with Mediterranean climates, the Iberian Peninsula and South Africa. Journal of the North American Benthological Society 25(2): 487-500.

8. Bonada N, Prat N, Resh VH and Statzner B (2006b) Developments in aquatic insect biomonitoring: a comparative analysis of recent approaches. Annual Review of Entomology 51: 495-523.

9. Kassahun A, Fekadu T, Zenebe T (2011) Adaptability, growth and reproductive success of the Nile tilapia, Oreochromis niloticus L. (Pisces: Cichlidae) stocked in Lake Tinshu Abaya, south Ethiopia. J Biol Sci 10: 153-166.

10. Benetti CJ and Garrido J (2010) The influence of stream habitat and water quality on water beetles' assemblages in two rivers in northwest Spain. Vie et milieu 60(1): 53-63.

11. Fengqing Li, Qinghua Cai, Wanxiang J and Xiaodong Qu (2012) Macroinvertebrate relationships with water temperature and water flow in subtropical monsoon streams of Central China: implications for climate change. Fundam Appl Limnol 180(3): 221-231.

12. Brierley GJ and Fryirs KA (2005) Geomorphology and river management: applications of the river styles framework. In: Blackwell Publishing, Oxford, UK, p. 398.

13. Stirling G. and Wilsey B (2001) Empirical relationships between species richness, evenness, and proportional diversity. American Naturalist 158: 286-300.

14. Stoffels RJ, Clarke KH and Closs GP (2005) Spatial scale and benthic community organization in the littoral zones of large oligotrophic lakes: potential for cross-scale interactions. Freshwater Biology 50: 1131-1145.

15. Yirga E and Brook L (2018a) Phytoplankton community composition and nutrient conditions as an indicator of ecosystem productivity in Lake Tinishu Abaya, rift valley, Ethiopia. Int J Fish Aquatic Stud 6: 173186.

16. Yirga E and Brook L (2018b) Zooplankton communities as an indicator of ecosystem productivity in Lake Tinishu Abaya, Rift Valley, Ethiopia. Int J Fish Aquac 10: 53-70 
17. Egertson CJ, Kopaska JA and Downing JA (2004) A century of change in macrophyte abundance and composition in response to agricultural eutrophication. Hydrobiologia 524: 145-156.

18. Edmondson WT (1959) Fresh water biology. In: (2 ${ }^{\text {nd }}$ edn). John Wiley and Sons Inc, New York, USA.

19. Gooderham J and Tysrlin E (2002) The water bug book. A guide to the freshwater macroinvertebrates of temperate Australia. In: Csiro publishing, Australia, p.77

20. Bouchard RW (2004) Guide to aquatic macroinvertebrates of the upper Midwest. Water resources center, University of Minnesota, St. Paul, Minnesota, US, pp. 208.

21. Klemm DJ, Lewis PA, Fulk F and Lazorchak JM (1990) Macro-invertebrate field and laboratory methods for evaluating the biological integrity of surface waters. EPA/600/4-90/030. U.S. Environmental protection agency: Office of research and development, Washngton, US.

22. Bode RW, Novak MA and Abele LE (1996) Quality Assurance Work Plan for Biological Stream Monitoring in New York State. NYS Department of Environmental Conservation, Albany, NY, USA.

23. Mason CF (1996) Biology of Freshwater Pollution. In: ( $3^{\text {rd }}$ Edn.). Longman Group Ltd, England pp. 356.

24. Hilsenhoff, WL (1988) Rapid field assessment of organic pollution with a family level biotic index. J North Amer Benthol soc 7(1): 65-68.

25. Barbour MT, Gerristen J, Griffith GE, Frydenborg R, McCarron E, et al. (1996) A framework for biological criteria for Florida stream using benthic macro-invertebrates. J North Ameri Bentho Soci 15(2): 185211.

26. Rosenberg DM and Resh VH (1993) Introduction to freshwater biomonitoring and benthic macroinvertebrates. In: DM Rosenberg, $\mathrm{VH}$ Resh (eds), Chapman \& Hall, New York, USA, pp. 1-9.

27. Leps J and Smilauer P (2003) Multivariate Analysis of Ecological Data using CANOCO. In: ( $1^{\text {st }}$ edn). Cambridge University Press, United Kingdom, p. 283.

28. Mazumdar A, Samal NR, Roy D and Gangopadhyay A (2007) Physicochemical Characteristics of Water in a shallow lake Rabindra Sarobar in Metropolis Kolkata. Journal of Institute of Engineering. 88: 32-40.

29. Samal NR, Roy D, Mazumdar A and Bose B (2004a) Seasonal response of water temperature of Rabindra Sarobar, the National Lake, in relation to $\mathrm{pH}$, dissolved oxygen, biochemical oxygen demand, and chemical oxygen demand. Journal of Public Health Engineering 2: 39-42.

30. Peeters FD, Livingstone M, Goudsmit GH, Kipfer R and Forster R (2002) Modeling 50 years of historical temperature profiles in a large central European lake. Limnology and Oceanograhy 47: 186-197.

31. Bachmann RW, Hoyer DE and Canfield JR (2000) The potential for wave disturbance in shallow Florida lakes. Lake and Reservoir Management 16(4): 281-291.

32. Klanderud K and Totland O (2005) Simulated climate change altered dominance hierarchies and diversity of an alpine biodiversity hotspot. Journal of Ecology 86(8): 2047-2054.

33. Hopkins PS, Kratz KW and Cooper SD (1989) Effects of an experimental acid pulse on invertebrates in a high-altitude Sierra Nevada stream. Hydrobiologia 171: 45-58.

34. Wigington PJ, DeWalle DR, Murdoch PS, Krester WA, Simonin HA, et al. (1996) Episodic acidification of small streams in the northeastern United States. controls of episodes Ecol App 6: 389-407.

35. Melack JM (1996) Recent developments in tropical limnology. Verh int ver Limnol 26: 211-217.
36. Hart B, Bailey P, Edwards P, Hortle K, James K, et al. (1991) A review of the salt sensitivity of the Australian freshwater biota. Hydrobiologia 210: 105-144.

37. Brian D and Tom D (2012) Sediment Effects on Macroinvertebrates Implications for the Indian Creek Sediment Target. Technical memorandum. Lower Boise Watershed Council.

38. Suren AM and Jowett IG (2001) Effects of deposited sediment on invertebrate drift: an experimental study. N Z J Mar Freshwater Res 35: 725-737.

39. Quinn JM, Davies-Colley RJ, Hickey CW, Vickers ML and Ryan PA (1992) Effects of clay discharges on streams. Hydrobiologia. 248: 235-247.

40. Miserendino NL, Pizzolon LA (2004) Interactive effects of basin features and land-use change on macroinvertebrate communities of headwater streams in the Patagonian Andes. River Res Appl 20: 967-983.

41. Rempel LL and Church M (2009) Physical and ecological response to disturbance by gravel mining in a large alluvial river. Can. Fis Aqua Sci 66: 52-71.

42. Stewart JS, Wang L, John L, Horwatich JA and Bannerman R (2001) Influence of watershed, riparian-corridor, and reach-scale characteristics on aquatic biota in agricultural watersheds. J Am Water Resour Assoc 37: 1475-1487.

43. Smith VH, Joye SB and Howarth RW (2006) Eutrophication of freshwater and marine ecosystems. Limnology and Oceanography. 51: 351355 .

44. Donohue I, Andrew J, Martin L, Pusch T and Irvine K (2009) Nutrient enrichment homogenizes lake benthic assemblages at local and regional scales. Journal of Ecology 90(12): 3470-3477.

45. Brauns M, Garcia XF, Pusch MT and Walz N (2007a) Eulittoral macroinvertebrate communities of lowland lakes: discrimination among trophic states. Freshwater Biology 52(6): 1022-1032.

46. White J and Irvine K (2003) The use of littoral mesohabitats and their macroinvertebrate assemblages in the ecological assessment of lakes. Aquatic Conservation. Marine and Freshwater Ecosystems 13: 331351.

47. Chandra S, Vander Zanden MJ, Heyvaert AC, Richards BC, Allen BC, et al. (2005) The effects of cultural eutrophication on the coupling between pelagic primary producers and benthic consumers. Limnology and Oceanography 50: 1368-1376.

48. Staub R, Appling JW, Hofsteiler AM, Hess IJ (1970) The Effect of Industrial Waster of Memphis and Shelby country on primary phytoplankton producers. Bioscience 20: 905-912.

49. Salusso MM, and Moraña LB (2000) Características físicas, químicas y fitoplancton de ríos y embalses de la Alta Cuenca del río Juramento (Salta, Argentina). Natura Neotropicalis 31(1-2): 20-44.

50. Chatzinikolaou Y and Lazaridou M (2007) Identification of the self-purification stretches of the Pinios River, Central Greece. Mediterranean Marine Science 8(2): 19-32.

51. Heino J, Muotka T, and Paavola R (2003) Determinants of macroinvertebrate diversity in headwater streams: regional and local influences. Journal of Animal Ecology. 72: 425-343.

52. Hooda PS, Moynagh M, Svoboda IF and Miller A (2000) Macroinvertebrates as Bioindicators of Water Pollution in Streams Draining Dairy Farming Catchments. Citemiistry and Ecology 17: 17-30.

53. OBBNPM (Ontario Benthos Biomonitoring Network Protocol Manual) (2004) The Use of the Biotic Index as an Indication of Water Quality. Association for Biology Laboratory Education, Pennsylvania, Canada.

54. Pérez-Quintero JC (2007) Diversity, habitat use and conservation of freshwater mollusks in the lower Guadiana River basin (SW Iberian 
Peninsula). Aquatic Conservation: Marine and Freshwater Ecosystems 17: 485-501.

55. Soldner M, Stephen I, Ramos I, Angus R, Wells NC, et al. (2004) Relationship between macroinvertebrate fauna and environmental variables in small streams of the The Dominican Republic. Water Research. 38: 863-874.

56. Venkatesharaju K, Ravikuma P, Somasheka R, Prakash L (2010) Physicochemical and Bacteriological Investigation on the river Cauvery of Kollegal Stretch in Karnataka. Journal of Science Engineering and Technology 6 (1): 50-59.
57. Yirga E and Brook L (2018c) Water Quality and Productivity Assessment of Lake Tinishu Abaya for Multiple Designated Water Uses, Ethiopia. J Environ Anal Toxicol 8(3): 1-12.

58. Yirga E and Brook L (2018d) Seasonality in the photosynthetic productivity and biomass of phytoplankton in Lake Tinishu Abaya (Rift Valley, Ethiopia): The basis for fish production. Int J Fish Aquac 10: 95-108.
CC (1) This work is licensed under Creative Commons Attribution 4.0 Licens
DOI: 10.19080/OFOAJ.2019.10.555782
Your next submission with Juniper Publishers will reach you the below assets

- Quality Editorial service

- Swift Peer Review

- Reprints availability

- E-prints Service

- Manuscript Podcast for convenient understanding

- Global attainment for your research

- Manuscript accessibility in different formats ( Pdf, E-pub, Full Text, Audio)

- Unceasing customer service

Track the below URL for one-step submission https://juniperpublishers.com/online-submission.php 